Article

\title{
Energy Efficiency Indicators for Water Pumping Systems in Multifamily Buildings
}

\author{
Danilo Ferreira de Souza ${ }^{1,2, *(\mathbb{D})}$, Emeli Lalesca Aparecida da Guarda ${ }^{3}$, Ildo Luis Sauer ${ }^{2}$ and Hédio Tatizawa ${ }^{2} \mathbb{D}$ \\ 1 Department of Electrical Engineering, Campus Cuiaba, Federal University of Mato Grosso, \\ Cuiabá 78060-900, Brazil \\ 2 Institute of Energy and Environment-IEE, University of Sao Paulo-USP, São Paulo 05508-010, Brazil; \\ illsauer@iee.usp.br (I.L.S.); hedio@iee.usp.br (H.T.) \\ 3 Environment Comfort Laboratory, Federal University of Santa Catarina, Florianopolis 88040-900, Brazil; \\ emeliguarda@gmail.com \\ * Correspondence: danilo.ferreira.souza@hotmail.com
}

Citation: de Souza, D.F.; da Guarda, E.L.A.; Sauer, I.L.; Tatizawa, H.

Energy Efficiency Indicators for Water Pumping Systems in Multifamily Buildings. Energies 2021, 14, 7152 https://doi.org/10.3390/en14217152

Academic Editors: Matthias Haase and Petter Wallentén

Received: 29 September 2021

Accepted: 25 October 2021

Published: 1 November 2021

Publisher's Note: MDPI stays neutral with regard to jurisdictional claims in published maps and institutional affiliations.

Copyright: (c) 2021 by the authors. Licensee MDPI, Basel, Switzerland. This article is an open access article distributed under the terms and conditions of the Creative Commons Attribution (CC BY) license (https:// creativecommons.org/licenses/by/ $4.0 /)$.

\begin{abstract}
With the current concerns about sustainable development and energy consumption in buildings, water pumping systems have become essential for reducing energy consumption. This research aims to develop guidelines for the energy assessment of water pumping systems in multifamily buildings. The methodological procedures are: (i) definition of the efficiencies of electric motors; (ii) definition of pump efficiency levels; (iii) determination of energy consumption; and (iv) construction of the efficiency scale and guidelines for projects and assessments. The results obtained were that centrifugal pumps with $40 \%$ efficiency have higher energy consumption, regardless of the efficiency class of the electric motors, showing a $20 \%$ increase in electrical energy consumption. Lower efficiencies directly impact the energy efficiency rating of the water pumping system. Thus the $40 \%$ efficiency obtained energy efficiency rating "Very Low-VL" for all motor efficiency classes (between IE1 and IE5). At 60\% efficiency, the energy efficiency level of the system was "Average-A", gradually increasing to "Very High- $\mathrm{VH}^{\prime}$, as the energy consumption in the pumps decreased and the motors' energy efficiency classes increased. It is concluded that designers and professionals in the area must consider the efficiency of the pumps, as they play a fundamental role in the classification of the system's energy efficiency. It is also recommended to verify the energy efficiency of the water pumping system and implement design guidelines so that the pumping system achieves lower energy consumption, contributing to the building's energy efficiency and sustainability.
\end{abstract}

Keywords: motor efficiency level; pump efficiency; MEPS; guidelines

\section{Introduction}

Access to water and energy is something necessary for the quality of life of a population and the economic growth of a region [1]. As a consequence, the energy demand has been increasing to allow this access. In the Brazilian context, commercial buildings, public agencies, and residences represented in 2019 approximately 52\% of total electricity consumption [2].

In vertical buildings, one of the sources of energy consumption is water pumping systems. Urban water supply systems typically consume between $1 \%$ and $4 \%$ of a municipality's electricity and are typically the largest single consumer of electricity. From collection to final use by users in large cities, urban pumping systems can consume $3.3 \mathrm{kWh} / \mathrm{m}^{3}$ [3]. In water distribution concessionaires, the expenditure on electricity in pumping systems contributes to about $90 \%$ of the electricity consumed in this sector [4].

Currently, 55\% of the world population is concentrated in cities in urban areas, according to a report by the United Nations (UN) [5]. It is estimated that 2.5 billion people will be added to the urban population by 2050, leading to more than half an increase in the number of people living in urban areas today. Thus, it is observed that the expansion of 
water supply infrastructure should be expanded, as those related to water pumping will intensify. Currently, the internal demand for domestic water-excluding garden irrigation and other external uses-represents $30 \%$ to $70 \%$ of the total urban water demand in developed countries [6].

In this context, the trend of continuous urbanization will increase the number of megacities with more than 10 million inhabitants, which may also increase the number of vertical multifamily housing buildings, making this building an attractive option [7,8]. It is observed that the higher the building and the denser its occupation, the higher the energy demand will be, including the energy consumption of the water pumping systems.

Electric motors are responsible for about $70 \%$ of the electricity consumed worldwide in industry and $46 \%$ of the world's electricity. Pumping systems alone consume almost $22 \%$ of all electrical energy consumed in electric motors in the world [9]. Electric motors are considered highly efficient equipment. The energy efficiency of centrifugal pumps is not considered high when compared to the efficiency of electric motors. Overall, pumps with $50 \%$ or even fewer efficiencies are typical depending on design and horsepower, and efficiency decreases over the pump lifecycle [10].

Aiming to advance the efficiency of electrical equipment, the minimum standard entitled the Minimum Energy Performance Standard (MEPS) and energy labels were defined, which is seen as one of the main ways to support energy efficiency directly at the product level. Using MEPS and energy product labels is a way to support rational consumer choice and overcome information barriers. These efforts are often mandatory, but they can also be voluntary [11], being updated over the years, according to improvements in construction materials and equipment designs, thus aiming to manufacture increasingly efficient equipment commercially.

In electric motors, MEPS is based on efficiency classes, enabling different levels, which increase according to technological advances and market acceptance. Efficiency classes for motors internationally are harmonized with the IE code in IEC 60034-30-1 [12], widely accepted as the global standard, making efficiency classes comparable worldwide. The standard defines efficiency classes IE1 to IE4, where IE1 is the least efficient and IE4 is the motor efficiency class with the highest efficiency. Similarly, in the United States, the efficiency classes IE1 to IE4 are called Standard, High Efficiency, Premium Efficiency, Super-Premium Efficiency, according to NEMA [13]. The new IE5 class has not yet been defined in detail but is planned for potential products in a future edition of the standard. For IE5 electric motors called Ultra-Premium Efficiency, the goal is to reduce losses by about $20 \%$ compared to the IE4 class $[14,15]$. Some manufacturers already offer IE5 class electric motors.

Efficiency classes are specified by the shaft power of the electric motor and by the number of poles on which the motor is built, responsible for speed. Most motors are 4-pole, representing between 50 and $70 \%$ of total electric motors. In motors that drive centrifugal pumps, most are 2-pole, which are the fastest alternating current electric motors, representing between 15 and $35 \%$ of the total number of motors [16].

A pumping system has several types of equipment besides the electric motor and the centrifugal pump that form the motor unit. Figure 1 shows the equipment/components presented for a typical system.

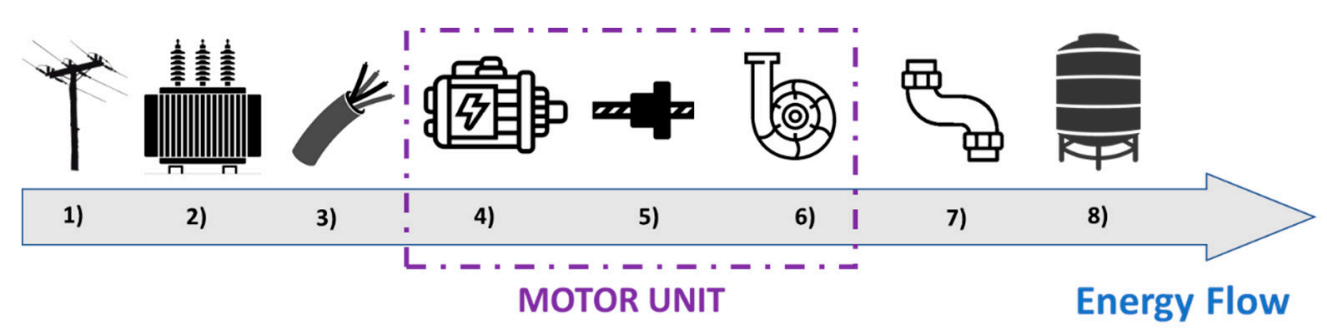

Figure 1. Equipment/components of a building pumping system. 
The equipment/components with the most significant possibility of intervention in order to reduce energy losses are the electric motor and the centrifugal pump [17], as they are the equipment that presents the highest losses in a pumping system. Table 1 presents the description of the components in Figure 1 and the approximate typical efficiency of each one of them.

Table 1. Losses in the building's water pumping system.

\begin{tabular}{|c|c|c|c|c|}
\hline \# & $\begin{array}{l}\text { Component in } \\
\text { Pumping System }\end{array}$ & Efficiency Level (\%) & Comments & Authors \\
\hline 1 & $\begin{array}{c}\text { Electric power } \\
\text { distribution system }\end{array}$ & - & $\begin{array}{l}\text { There are losses in the electricity } \\
\text { distribution system. However, this } \\
\text { analysis is restricted to the } \\
\text { pumping system. }\end{array}$ & - \\
\hline 2 & Electrical transformer & $\sim 98$ & $\begin{array}{l}\text { There is no direct energy conversion. } \\
\text { The input and output are electrical } \\
\text { energy, and the transformer is } \\
\text { naturally high-efficiency equipment. }\end{array}$ & $\begin{array}{l}\text { Krishnamoorthy and } \\
\text { Jayabal [18]; } \\
\text { Kazakbaev et al. [19] }\end{array}$ \\
\hline 3 & Electric cables & $\sim 98$ & $\begin{array}{l}\text { For short distances, electrical cable } \\
\text { losses are low. }\end{array}$ & $\begin{array}{l}\text { Krishnamoorthy and } \\
\text { Jayabal [18]; } \\
\text { Kazakbaev et al. [20] }\end{array}$ \\
\hline 4 & Electric motor & $>80$ & $\begin{array}{l}\text { The electric motor converts electrical } \\
\text { energy to mechanical energy. It } \\
\text { presents electrical losses, magnetic } \\
\text { losses, and mechanical losses. }\end{array}$ & Almeida et al. [14] \\
\hline 5 & Coupling & $\sim 99$ & $\begin{array}{l}\text { It performs the coupling between } \\
\text { the electric motor and the } \\
\text { centrifugal pump. }\end{array}$ & Kalaiselvan et al. [17] \\
\hline 6 & Centrifugal pump & $35-70$ & $\begin{array}{l}\text { Centrifugal pumps have mechanical } \\
\text { and hydraulic losses. They are } \\
\text { dependent on the flow and pressure } \\
\text { of the piping system. }\end{array}$ & Mitrovic et al. [21] \\
\hline 7 & Piping system & $\sim 73$ & $\begin{array}{l}\text { High pressures in the piping system } \\
\text { cause vibrations and wear. However, } \\
\text { they are difficult to measure. }\end{array}$ & WSU Energy Program [22] \\
\hline 8 & Upper reservoir & - & $\begin{array}{l}\text { Losses in the upper reservoir occur } \\
\text { due to water evaporation. If not, } \\
\text { effectively energy loss. }\end{array}$ & - \\
\hline
\end{tabular}

Labels and MEPS for these devices tend to be stabilized by the theoretical limits of the dominant technologies so that the following improvements will come through new technologies in the case of electric motors $[14,19]$, replacing the traditional three-phase Induction Motors with Squirrel Cage Rotor (SCIMs), by Permanent Magnet Synchronous Motors (PMSM), and by Motors Synchronous Reluctance (SynRM), to achieve the highest levels of IE4 and the future IE5 [20,21].

Improvements between IE1 and IE4 classes using SCIMs technology were promoted by using more copper in the stator windings, improvement in the quality of ferromagnetic materials, optimization of electrical designs, and the aerodynamics of the ventilation system [23-25]. However, it is easier to increase the efficiency of the motor system with the application of other technologies, such as PMSM and SynRM, where joule losses in the motor rotor do not exist, as they operate synchronously, thus increasing efficiency [14].

Several works in the literature analyze the impact of IE classes on the electrical system, discussing the economic and environmental impacts.

Andrade and Thé Pontes [26] simulated the replacement of IE2 motors for IE3 in the Brazilian case. They concluded that the energy efficiency measure could generate 
approximately $164 \mathrm{GWh}$ /year savings if fully adopted from 2020. About $2600 \mathrm{GWh}$ accumulated until 2030 , reducing $0.64 \%$ of the total electricity consumption of the Brazilian industry until 2030, which represents $5.3 \%$ of the total electricity savings expected by the Brazilian government.

Mahlia and Yanti [27] simulated the advancement of MEPS in Malaysia for electric motors, demonstrating the reduction of the country's electricity consumption, the indirect reduction of emissions, and the reduction in electricity bills. The study proved the remarkable benefit to consumers, manufacturers, government, and the environment by implementing energy efficiency standards for electric motors. Mahlia and Yanti [27] also noted that improving the efficiency of electric motors in the industrial sector is a valuable strategy for reducing the impacts of electricity generation in Malaysia. Energy efficiency standards benefit the consumer, national economy, natural environment, and local manufacturing.

Bortoni et al. [28] estimated the amount of energy saved in SCIM due to Brazil's energy efficiency labeling program and its contribution to reducing peak demand, analyzing the replacement of IE1 class motors by IE2 class motors. Bortoni et al. [28] observed that efficiency increases in motors in the range of 1-10 HP are significant for the labeling program because, in absolute numbers, they represent $76 \%$ of induction motors installed in Brazil.

Safin et al. [29] compared the energy consumption in a water pumping system using SCIM class IE2 starting directly from the electrical network with a SynRM class IE5 starting with Electronic Speed Variator (VSD) with a power of $0.75 \mathrm{~kW}$. They achieved savings of $13.9 \%$ using the IE5 class electric motor compared to the IE2 class.

Goman et al. [30] analyzed the energy consumption of 8 electric motors from different manufacturers, with a shaft power of $2.2 \mathrm{~kW}$, with 3 SCIM class IE3, 2 SCIM class IE4, and 3 PMSM class IE4 being in the electrical drive of a pumping unit with variable speed for a water supply system. Goman et al. [30] simulated the energy consumption by a pump unit in four typical work cycles, considering 25\%,50\%, 75\%, and 100\% electric motor loading, and concluded that for the IE4 standard, the PMSM do not provide significant advantages over peer SCIM.

Kazakbaev et al. [20] compared SCIMs class IE2 and IE3 fed directly from the network with PMSM and SynRM class IE4, fed through an Electronic Speed Variator (VSD), evaluating the energy savings over the life cycle of the motor-pump set and the payback period when replacing an IE2 class SCIM motor with an IE4 class motor. Kazakbaev et al. [18] concluded that the IE4 electric motor, in addition to saving more energy due to its higher efficiency class, with the higher power factor, losses in the cable and the transformer were also reduced, recording a payback time of less than one year.

The efficiency of the centrifugal pump is a determining element in the efficiency of the pumping system. Thus, another way to improve energy efficiency is in the optimal sizing of the installation, seeking to operate the centrifugal pump in the region where efficiency is maximum, also known as the Best Efficiency Point (BEP) [31].

According to Wong et al. [32], from studies carried out in Hong Kong, approximately half of energy losses in the water supply is reserved for pumping systems, as well as aging systems and misuse. In many cases, the centrifugal pump is used at low or medium loads, despite having higher efficiency values at loads close to the nominal. Glover and Lukaszczyk [33] estimated that $75 \%$ of centrifugal pumps are oversized by more than $20 \%$ and that $80 \%$ of electric motors driving centrifugal pumps are operating outside the region of maximum efficiency.

In the Brazilian case, there are still no standards or regulations to establish the minimum efficiency of centrifugal pumps. In the European case, positive experiences such as the Minimum Efficiency Index (MEI) that limits circulation pumps and centrifugal pumps with lower efficiency in the market have already shown good results $[32,33]$.

Buildings are known to account for more than $30 \%$ of global energy demand and global greenhouse gas emissions [34,35] and improving energy efficiency in building pumping 
systems is a strategy to reduce Greenhouse Gases (GHG) [36,37]. Therefore, the adoption of design strategies to promote energy efficiency is fundamental.

Low efficiency in building water pumping systems is common, as it is generally not visible to residents, and most often, the pumping systems are installed by builders, who are not users of the building, nor do they pay the bills for the low system efficiency. With this, the barriers to the energy efficiency of these systems are higher $[11,38]$.

In the context of energy consumption in multi-family buildings, attention to energy efficiency is normally directed towards systems that consume the most energy, such as heat pumps, lighting, refrigeration, and cooking. Thus, environmental certifications for sustainable buildings usually focus credits on these energy consumptions.

The energy efficiency of the building's water pumping system is usually not assessed by environmental certifications for sustainable buildings. For this reason, means of advancing energy efficiency in these systems for multifamily buildings is a research potential. As building water pumping systems are essential for multifamily buildings, considering the growing energy consumption of buildings, the improvement in the energy efficiency of these systems is essential in the context of building certifications and on the path to sustainable buildings.

Thus, research aims to develop project guidelines for evaluating water pumping systems in multifamily buildings.

\section{Materials and Methods}

The focus of this research is to develop design guidelines for water pumping systems to serve vertical multifamily buildings. Thus, the methodological process consists of five steps, namely: (i) definition of the object of study; (ii) definition of the efficiencies of twopole electric motors; (iii) definition of pump efficiency levels; (iv) determination of energy consumption; and (v) construction of the efficiency scale and design guidelines, as shown in Figure 2.

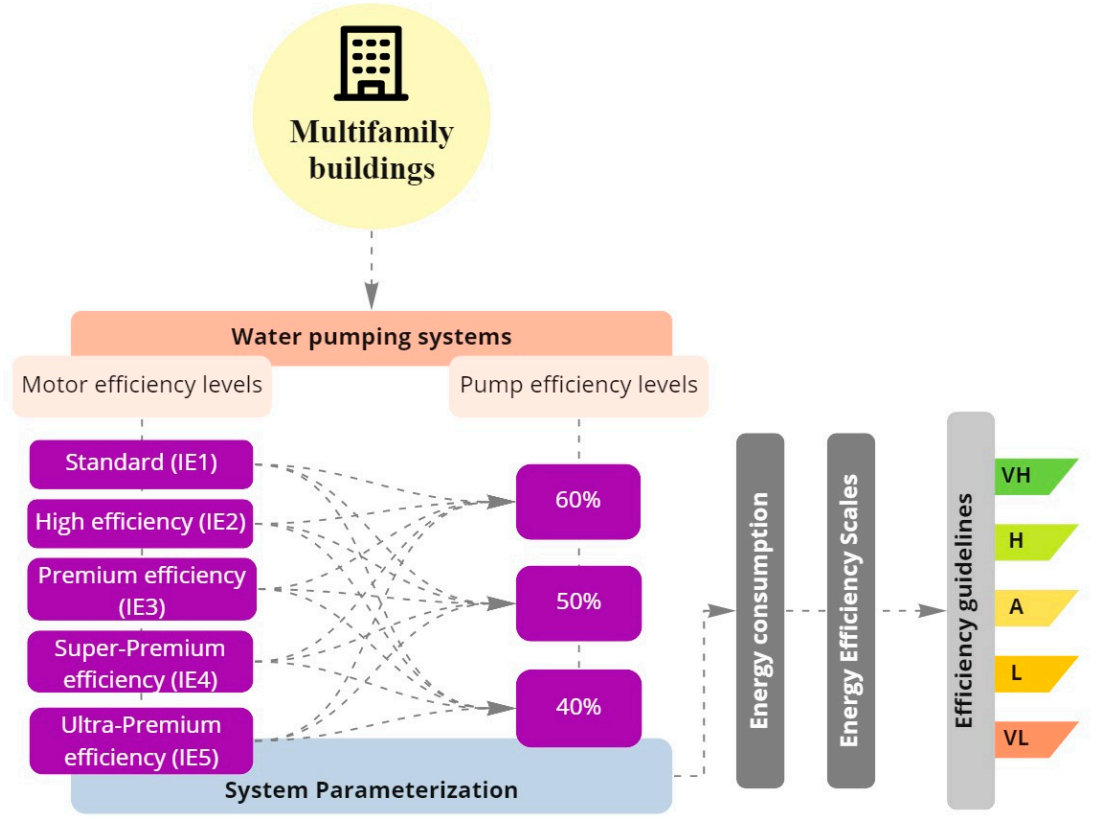

Figure 2. Methodological process flowchart.

\subsection{Study Object}

The object of study was a vertical multifamily building (Figure 3) for the design of the water pumping system. The building has 16 floors, distributed into a ground floor and 15 intermediate floors, featuring four housing units per floor, elevators, emergency exits, and entrance halls, totaling $60 \mathrm{~m}$ in height. In the housing units, an occupation of four people was considered, totaling 240 people in the building. 


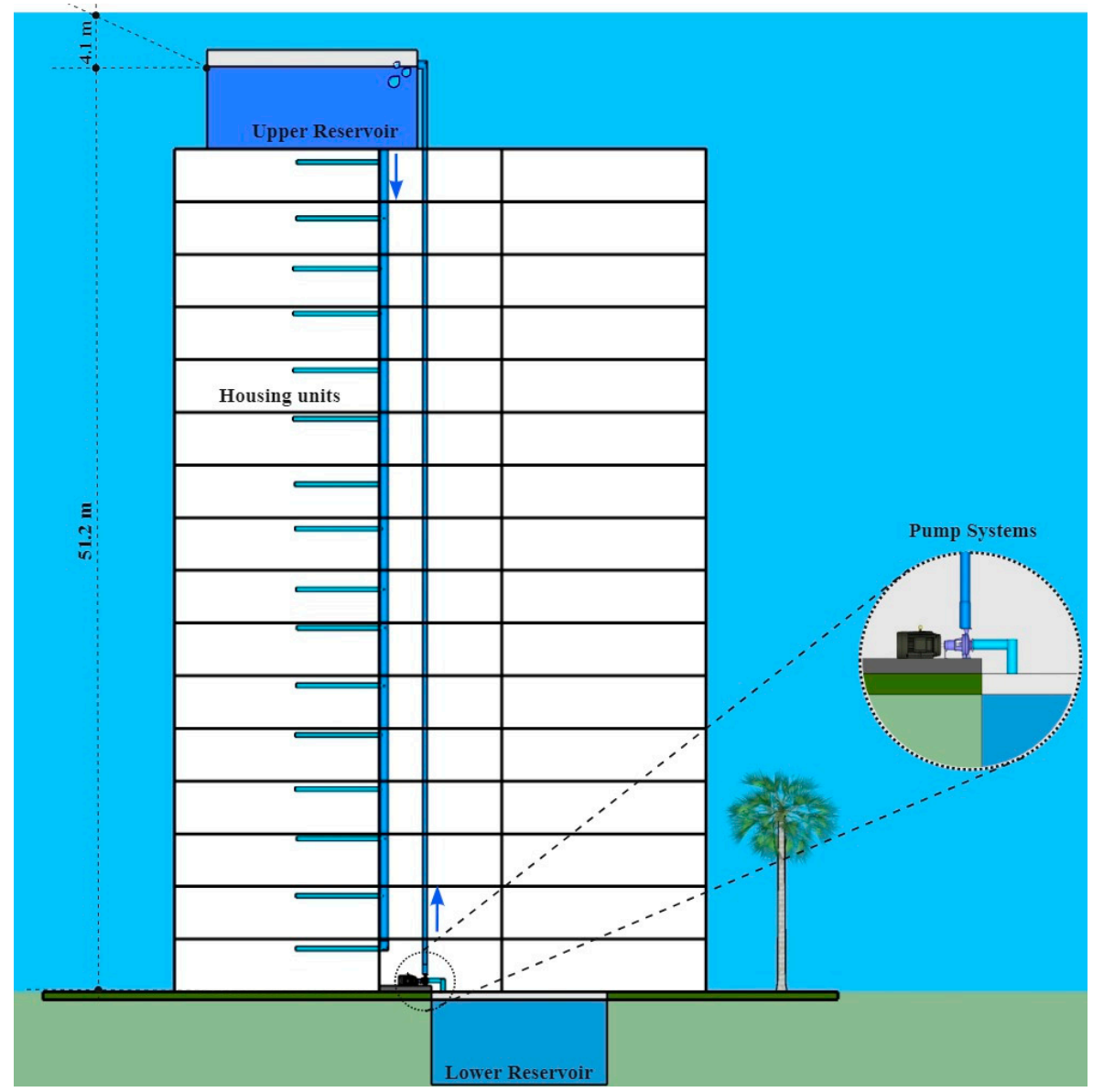

Figure 3. Representation of the building object of study.

On the building's roof, there is an upper water reservoir, which distributes to the housing units, and on the ground floor, there is a lower reservoir that receives and stores the water from the municipal sanitation concessionaire. Thus, in this study, a water consumption of $200 \mathrm{~L}$ per person per day was considered, totaling $48 \mathrm{~m}^{3}$ per day in the building. Thus, the capacities considered in the reservoirs are less than $2 / 3$ of the daily volume $\left(32 \mathrm{~m}^{3}\right)$ and greater than $1 / 3$ of the daily volume $\left(16 \mathrm{~m}^{3}\right)$.

In this context, the sizing of head losses [39] was given by the difference in level between the lower and upper reservoir of $51.2 \mathrm{~m}$ and head losses due to pipes, bends, special hydraulic parts, and others in $4.1 \mathrm{~m}$, the losses of total loads being considered in $55.3 \mathrm{~m}$. Suction and discharge hydraulic piping materials are in accordance with Brazilian standards [40].

In view of the daily consumption and the losses of distributed loads, the sizing of the centrifugal pump is obtained, given by the power of the equipment (kW), according to Equation (1). The operation of the pump system was considered for four hours a day, the flow of $12 \mathrm{~m}^{3} / \mathrm{h}$, and three different efficiencies, being $40 \%, 50 \%$, and $60 \%$. The power increase was not considered.

$$
\mathrm{P}_{\text {pump }}=\left(\frac{\gamma \times \mathrm{Q} \times \mathrm{H}_{\text {total }}}{270 \times \mathrm{n}_{\text {pump }}}\right) * 0.736
$$

where:

$P_{\text {pump }}=$ pump power $(\mathrm{kW})$;

$\gamma=$ specific water weight $(1 \mathrm{~kg} / \mathrm{L})$;

$\mathrm{Q}=$ flow $\left(\mathrm{m}^{3} / \mathrm{h}\right)$;

$\mathrm{H}_{\text {total }}=$ total height including head losses (m); 
$\mathrm{n}_{\text {pump }}=$ Pump efficiency $(\%)$.

In addition to the pumps, it is necessary to dimension the electric motors, which are responsible for the mechanical drive of the centrifugal pump to lift water. For this, the power of the motors was considered to be the same as that of the pumps, determined by Equation (1), as well as only two-pole motors, as they are the most used in pumping systems. As the operating power of the electric motor is very close to the nominal power of the motor, polynomial interpolation will not be necessary to find a new efficiency value for the electric motor, considering the nominal efficiency for the analysis.

Thus, to identify the efficiency of two-pole electric motors for each calculated power, the Brazilian Decree number 4508 of 2002 [41] was considered for classes IE1 and IE2; the Interministerial Ordinance number 1 of 2017 [42] for class IE3. Standard IEC 60034-30-1 [12] was applied for class IE4. For class IE5 motors called Ultra-Premium Efficiency, a 20\% reduction in losses was considered in relation to class IE4 [14].

\subsection{Estimation of Energy Consumption and Energy Efficiency Scales}

Energy consumption was defined based on the power of the motor-pump set, defined in Equation (1), by the efficiency of the electric motor at full load and by the hours and days of use, according to Equation (2). In addition, 0.736 was used to convert the power of electric motors in $\mathrm{kW}$.

$$
\mathrm{E}=\left(\frac{\mathrm{P}_{\text {motor }} \times 0.736}{\mathrm{n}_{\text {motor }}}\right) \times\left(\mathrm{h} \times \mathrm{N}_{\text {days }}\right)
$$

where:

$\mathrm{E}=$ electricity consumption $(\mathrm{kWh})$;

$\mathrm{P}_{\text {motor }}=$ motor power $(\mathrm{kW})$;

$\mathrm{n}_{\text {motor }}=$ engine efficiency $(\%)$;

$\mathrm{h}=$ daily hours of use;

$\mathrm{N}_{\text {days }}=$ number of days of use.

The energy consumption and energy efficiency scale was elaborated based on the efficiency classes of the motors and on the efficiency range of the pumps of $40 \%, 50 \%$, and $60 \%$ considered in this study. This scale was created with the objective of classifying building water pumping systems, mainly for vertical multifamily buildings, classifying as Very High (VH), High (H), Average (A), Low (L), or Very Low (VL).

The definition of the intermediate classes results in the division of the difference between the highest and lowest energy consumption with the scale efficiency intervals, in five parts, according to Equation (3), with the value of the consumption difference and the coefficient " $\mathrm{E}$ ", the scale according to Table 2.

$$
\mathrm{E}=\frac{\left(\mathrm{H}_{\mathrm{E}}-\mathrm{L}_{\mathrm{E}}\right)}{5}
$$

where:

$\mathrm{E}=$ coefficient representing the intervals between classifications;

$\mathrm{H}_{\mathrm{E}}=$ highest energy consumption obtained $(\mathrm{kWh} /$ year);

$\mathrm{L}_{\mathrm{E}}=$ lowest energy consumption obtained ( $\mathrm{kWh} /$ year).

Table 2. Range limits of energy efficiency ratings for the water pump system.

\begin{tabular}{cccccc}
\hline \multirow{2}{*}{ Efficiency Class } & VH & $\mathrm{H}$ & $\mathrm{A}$ & $\mathrm{L}$ & VL \\
\cline { 2 - 6 } & $<\mathrm{H}_{\mathrm{E}}-(5 \times \mathrm{E})$ & $<\mathrm{H}_{\mathrm{E}}-(4 \times \mathrm{E})$ & $<\mathrm{H}_{\mathrm{E}}-(3 \times \mathrm{E})$ & $<\mathrm{H}_{\mathrm{E}}-(2 \times \mathrm{E})$ & $>\mathrm{H}_{\mathrm{E}}$ \\
\hline
\end{tabular}


Finally, with the help of a scale, guidelines for projects for water pumping systems for vertical multifamily buildings of up to 16 floors were elaborated in order to help designers and researchers achieve energy efficiency in these systems.

\section{Results and Discussion}

\subsection{Analysis of Energy Consumption of the Water Pump System}

Through pump efficiency of $40 \%, 50 \%$, and $60 \%$, the respective powers were obtained, resulting in $3.01 \mathrm{~kW}, 4.91 \mathrm{~kW}$, and $6.14 \mathrm{~kW}$. In this way, the powers of the electric motors were defined by means of the powers of the pumps, being $3.0 \mathrm{~kW}, 3.7 \mathrm{~kW}$, and $5.5 \mathrm{~kW}$, respectively, for each pump efficiency. Thus, using the procedure described in item 3.1, the efficiency classes of electric motors were obtained (Table 3).

Table 3. The efficiency of two-pole electric motors for different classes.

\begin{tabular}{cccc}
\hline Pump Efficiency & $\mathbf{6 0 \%}$ & $\mathbf{5 0} \%$ & $\mathbf{4 0} \%$ \\
\hline Pump power & $3.01 \mathrm{~kW}$ & $4.91 \mathrm{~kW}$ & $6.14 \mathrm{~kW}$ \\
Rated power of electric motors (2 poles) & $3.0 \mathrm{~kW}$ & $3.7 \mathrm{~kW}$ & $4.5 \mathrm{~kW}$ \\
IE1 & $82.5 \%$ & $84.5 \%$ & $85.0 \%$ \\
IE2 & $85.0 \%$ & $87.5 \%$ & $88.0 \%$ \\
IE3 & $88.5 \%$ & $88.5 \%$ & $88.5 \%$ \\
IE4 & $89.1 \%$ & $90.0 \%$ & $90.9 \%$ \\
IE5 & $92.1 \%$ & $92.0 \%$ & $92.7 \%$ \\
\hline
\end{tabular}

From these results, the energy consumption of the pumping system was obtained. It is noteworthy that the energy consumption of the building was not considered, with only the consumption of pumps and motors with different efficiencies being considered. Thus, the highest energy consumptions were from the pump with $40 \%$ efficiency of pumps and from the efficiency classes of motors IE1 to IE4, which obtained values above $7000 \mathrm{kWh} /$ year. In this scenario, IE5 presented lower values, with a difference of $626 \mathrm{kWh} /$ year in relation to IE1 (Figure 4). It is noteworthy that using the $40 \%$ efficiency pump, it is possible to obtain energy efficiency in the system of up to $4 \%$ with IE2 and IE3, up to $7 \%$ with IE4, and up to $5 \%$ with IE5 in relation to IE1.

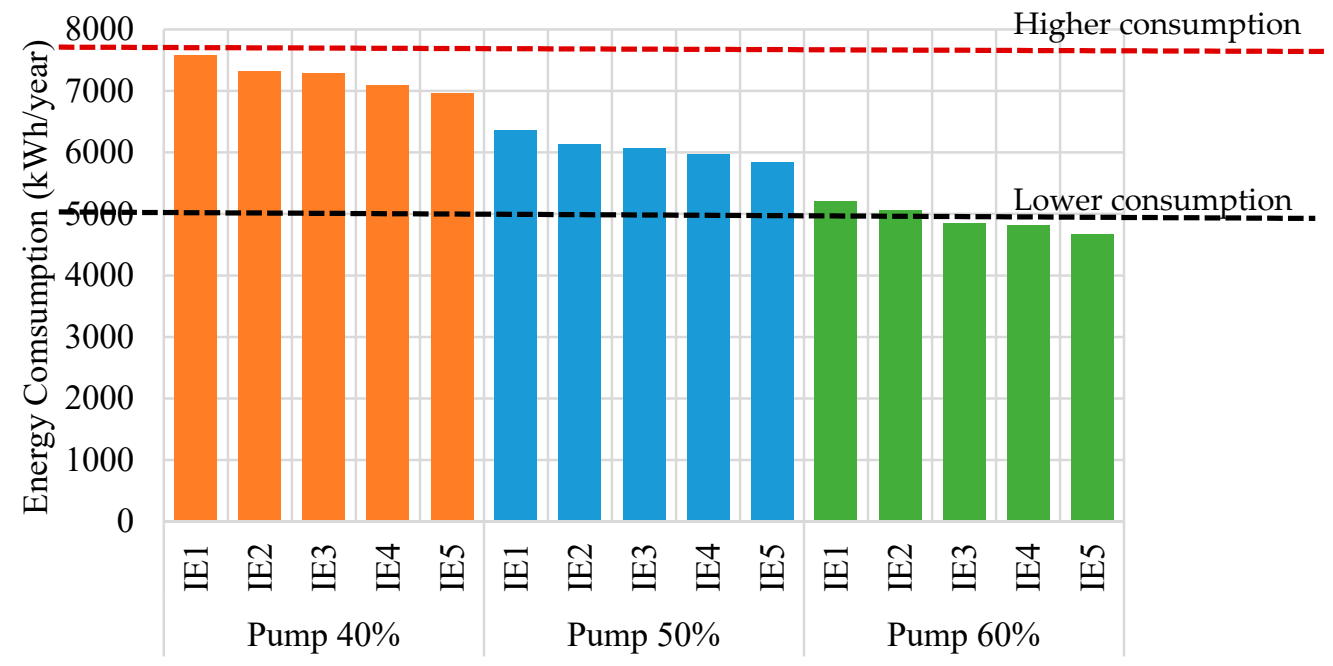

Figure 4. Energy consumption by pump efficiency range and electric motor classes.

It was observed that in the scenario of $50 \%$ pump efficiency, it presented median energy consumption values ranging from $6959 \mathrm{kWh}$ to $5970 \mathrm{kWh}$ from IE1 to IE5. The level of efficiency increased gradually according to the class of electric motors, obtaining a difference of $4 \%$ with IE2, 5\% with IE3, 7\% with IE4, and 9\% with IE5 (Figure 4 ). However, comparing the efficiency of $50 \%$ (IE5) with $40 \%$ (IE5), I obtained smaller reductions in 
energy consumption, $518 \mathrm{kWh}$ /year, compared to IE1 and difference between the scenarios of up to $108 \mathrm{kWh} /$ year.

The scenario using a pump operating at $60 \%$ efficiency presented lower energy consumption with the same reduction profile as the other scenarios, gradually increasing according to the classes of electric motors. In this way, better energy efficiency levels were obtained up to $3 \%$ with IE2, up to $7 \%$ with IE3, up to $8 \%$ with IE4, and up to $12 \%$ with IE5. Thus, this scenario presented better efficiency levels from IE4 on compared to other scenarios. Thus, the difference in energy consumption between IE5 and IE1 was $543 \mathrm{kWh}$ (Figure 4).

It was observed that the $40 \%$ scenario obtained greater energy consumption reductions with efficiency class IE5, followed by the $60 \%$ scenario and the $50 \%$ scenario. However, the highest energy consumptions were obtained in the $40 \%$ scenario; that is, the lower the pump efficiency, the greater the energy consumption of the system, so that the efficiency classes of electric motors had little influence on consumption when compared to savings with different pump efficiencies. Thus, in multifamily buildings that use pumps with an efficiency of approximately $40 \%$, it is recommended to use class IE4 to IE5 motors so that the average consumption of the pumping system is around $7000 \mathrm{kWh} /$ year.

\subsection{Classification of the Energy Efficiency of the Water Pumping System of the Object of Study}

The classification of energy efficiency of the water pumping system in the three pump efficiency scenarios was performed based on energy consumption. Thus, the intermediate classes were defined through the difference between the highest and lowest energy consumption, being $7585 \mathrm{kWh}$ /year and $4667 \mathrm{kWh} /$ year, respectively, and the coefficient "E"-Equation (3) and Table 2. Table 4 presents the 5 resulting energy efficiency classes.

Table 4. Energy efficiency ratings for the water pumping system of the object of study.

\begin{tabular}{cccccc}
\hline \multirow{2}{*}{$\begin{array}{c}\text { Energy Efficiency } \\
\text { Rating }\end{array}$} & $\mathrm{VH}$ & $\mathrm{H}$ & $\mathrm{A}$ & $\mathrm{L}$ & $\mathrm{VL}$ \\
\cline { 2 - 6 } & $\leq 4.667 \mathrm{kWh} /$ year & $4.667<5.251$ & $5.251<5.834$ & $5.834<6.418$ & $\geq 7.585$ \\
\hline
\end{tabular}

Thus, the energy efficiency rating "VL" was obtained for all efficiency classes of electric motors using the pump with $40 \%$ efficiency. Thus, water pumping systems that present these scenarios may present less energy efficiency, contributing to the increase in the energy demand of the building under analysis (Figure 5).

\begin{tabular}{|c|c|c|c|c|c|}
\hline Energy Efficiency Rating & IE1 & IE2 & IE3 & IE4 & IE5 \\
\hline \multirow[b]{2}{*}{ Pump 40\% } & 7.585kWh/year & 7.327 kWh/year & $7.285 \mathrm{kWh} /$ year & $7.093 \mathrm{kWh} /$ year & $6.959 \mathrm{kWh} /$ year \\
\hline & 舟 & & & & \\
\hline \multirow[b]{2}{*}{ Pump 50\% } & $6.358 \mathrm{kWh} /$ year & $6.140 \mathrm{kWh} /$ year & $6.071 \mathrm{kWh} /$ year & $5.970 \mathrm{kWh} /$ year & $5.840 \mathrm{kWh} /$ year \\
\hline & & & & & \\
\hline \multirow[b]{2}{*}{ Pump 60\% } & $5.210 \mathrm{kWh} /$ year & $5.057 \mathrm{kWh} /$ year & 4.857 kWh/year & $4.824 \mathrm{kWh} /$ year & $4.667 \mathrm{kWh} /$ year \\
\hline & A & ए! & ए! & 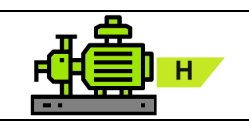 & 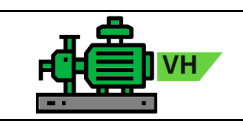 \\
\hline
\end{tabular}

Figure 5. Energy efficiency rating of the analyzed water pumping system.

In the $50 \%$ scenario, the electric motor class IE1 presented an efficiency rating of "VL", changing to "L" in the other classes (IE2 to IE5) (Figure 5). However, it is noteworthy 
that the lowest consumption was observed in the scenario $50 \%$ (IE5) and $50 \%$ (IE4). Thus, to achieve better levels of energy efficiency, it is recommended to use these scenarios. It was also observed that the difference in the efficiency levels of these scenarios was only $136 \mathrm{kWh}$ /year to become " $\mathrm{A}$ " efficiency level; that is, reducing energy consumption, consequently increasing the energy efficiency of the system as a whole including the building under analysis.

In the $60 \%$ scenario, the energy efficiency level of the system was " $\mathrm{A}$ ", gradually increasing to " $\mathrm{VH}^{\prime}$, according to the reduction in energy consumption and increase in the energy efficiency classes of electric motors (Figure 5). It is noteworthy that this scenario is the most optimistic in terms of energy efficiency, which presented the best levels achieved through water pumping systems in multifamily buildings.

Thus, it was observed that the efficiency of pumps played a preponderant role in a pumping system, regardless of the efficiency classes of electric motors. Thus, comparing the efficiency of the pumps, considering the $40 \%$ pump and the IE1 class motor, $15.6 \%$, and $35.0 \%$ were obtained in relation to the use of $50 \%$ and $60 \%$ efficiency pumps. These differences show a similar behavior if we consider the other efficiency classes of electric motors.

In this context, in order to assist designers in building water pumping systems for vertical multifamily buildings, project guidelines are presented. Thus, through the ratings obtained, it was observed that with the efficiency of pumps above $60 \%$ from the IE3 efficiency class, it is possible to obtain the energy efficiency rating " $\mathrm{VH}^{\text {". As for pumps }}$ with efficiency between $60 \%$ and $50 \%$ for all classes of electric motors, it is possible to obtain an energy efficiency rating of " $\mathrm{H}$ " and a lower increase in energy consumption of the water pumping systems in the building (Figure 6).

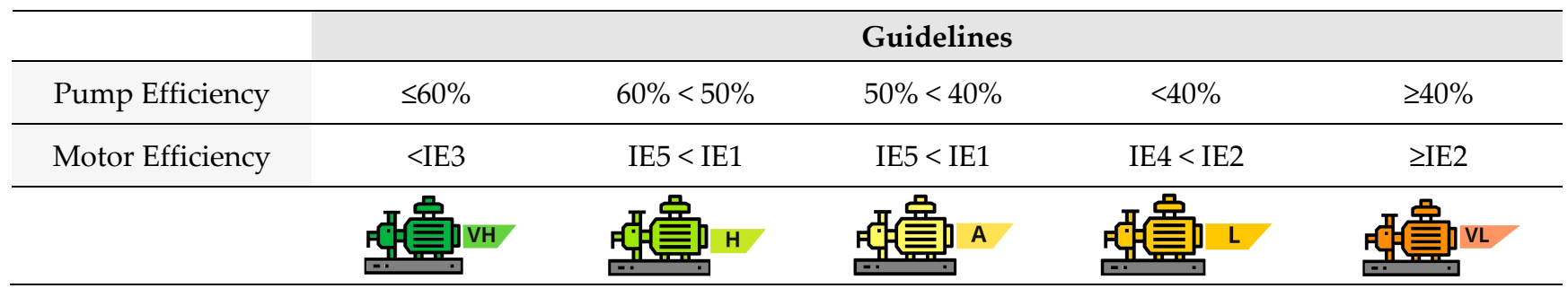

Figure 6. Guidelines for designing water pumping systems for multi-family buildings.

In the pump efficiency range between $40 \%$ and $50 \%$ for all motor energy efficiency classes, it is possible to obtain energy efficiency level " $\mathrm{A}$ ". Thus, it is observed that without major difficulties, it is possible to reach average levels of energy efficiency, which can help in total energy efficiency when considering the complete building, especially in cases of retrofit. Finally, centrifugal water pumps with efficiency greater than $40 \%$, considering efficiency classes IE2, IE3, and IE4 of electric motors, it is possible to obtain efficiency level " $L$ ". For pump efficiency and motor efficiency class less than $40 \%$ and IE2, respectively, it is only possible to obtain a "VL" efficiency level, being the worst energy efficiency rating.

Thus, it is observed that to have better levels of energy efficiency in pumping systems, it is necessary to apply higher pump efficiencies, while with classes above IE3, it is possible to achieve high levels of efficiency. Thus, it is recommended that designers and professionals in the area use pumps with greater efficiency and ensure that they are operating in the region where they have the best performance, as well as verifying the energy efficiency of the system as a whole, so that it achieves better levels of efficiency and reduces the energy consumption of the system, helping both in environmental sustainability and in the energy classification of the building under construction. 


\section{Conclusions}

Given the results presented, it is concluded that the efficiency of pumps is preponderant in the efficiency of the pumping system. The highest energy efficiency classes of electric motors IE4 and IE5 showed significant gains compared to the lower classes IE1 and IE2. However, the efficiency of the pumps played a fundamental role in the energy consumption of the system.

Pumps with efficiency of $50 \%$ and $60 \%$ presented better levels of energy efficiency in the system, depending on the efficiency class of the motors used. Thus, for the $50 \%$ scenario (IE1), it presented an efficiency class "VL", changing to "L" in the other classes (IE2 to IE5). In the $60 \%$ scenario, the energy efficiency level of the system was " $\mathrm{A}$ ", gradually increasing to " $\mathrm{VH}$ ", according to the reduction in energy consumption and increase in the energy efficiency classes of electric motors. Thus, it is observed that to have better levels of energy efficiency in the systems, it is necessary to apply higher pump efficiencies. In the efficiency range between $40 \%$ and $50 \%$ for all motor energy efficiency classes, it is possible to obtain an average energy efficiency level " $\mathrm{A}$ ".

It is concluded that the designers and professionals in the area must consider the efficiency of the pumps, as they play a fundamental role in the classification of the system's energy efficiency. In addition, in old buildings, the energy efficiency of pumping systems can be improved without changing the envelope or other equipment, thus reducing energy consumption.

In addition, it is recommended to verify the energy efficiency of the water pumping system and implement design guidelines to achieve lower energy consumption, contributing to the building's energy efficiency and sustainability. For future research, it is recommended to investigate other efficiency levels of pumps and motors and use other case studies of vertical multifamily buildings.

Usually, energy efficiency in water pumping systems in buildings is not evaluated by sustainable certifiers. Therefore, the proposed efficiency assessment guideline presents an initial and original contribution to increasing the energy efficiency of buildings.

Author Contributions: Conceptualization, D.F.d.S. and E.L.A.d.G.; methodology, D.F.d.S. and E.L.A.d.G.; formal analysis, E.L.A.d.G.; investigation, D.F.d.S. and E.L.A.d.G.; writing-original draft preparation, D.F.d.S. and E.L.A.d.G.; writing-review and editing, D.F.d.S. and E.L.A.d.G.; visualization, H.T. and I.L.S.; funding acquisition, H.T. and I.L.S. All authors have read and agreed to the published version of the manuscript.

Funding: The authors are grateful for the support received from the Institute of Energy and Environment of the University of Sao Paulo (IEE-USP) and Enel Electric Power Distribution of Sao Paulo in partnership with the National Electric Energy Agency (ANEEL), through the Priority Project for Energy Efficiency and Strategic R\&D—Call 001/2016, "Energy Efficiency and Mini generation in Public Institutions of Higher Education". Project number 00390-1086/2018.

Institutional Review Board Statement: Not applicable.

Informed Consent Statement: Not applicable.

Data Availability Statement: Not applicable.

Acknowledgments: The authors thank the National Council for Scientific and Technological Development (CNPq) for the scholarship made available to the first author, through the project 870814/1999-0, process 142323/2020-9, so that he could dedicate himself to his $\mathrm{PhD}$ research of and related fields.

Conflicts of Interest: The authors declare no conflict of interest.

\section{References}

1. Rio Carrillo, A.M.; Frei, C. Water: A key resource in energy production. Energy Policy 2009, 37, 4303-4312. [CrossRef]

2. EPE Balanço Energético Nacional 2020: Ano Base 2019; Empresa de Pesquisa Energética-EPE: Brasilia, Brazil, 2020.

3. Plappally, A.K.; Lienhard, V.J.H. Energy requirements for water production, treatment, end use, reclamation, and disposal. Renew. Sustain. Energy Rev. 2012, 16, 4818-4848. [CrossRef] 
4. Shimizu, Y.; Toyosada, K.; Yoshitaka, M.; Sakaue, K. Creation of Carbon Credits by Water Saving. Water 2012, 4, 533-544. [CrossRef]

5. ONU. World Urbanization Prospects-The 2018 Revision; United Nations: New York, NY, USA, 2019; ISBN 978-92-1-004314-4. Available online: https:/ / population.un.org/wup/Publications/Files/WUP2018-Report.pdf (accessed on 20 October 2021).

6. Zhao, J.; Xie, X.; Liu, R.; Sun, Y.; Wu, M.; Gu, J. Water and energy saving potential by adopting pressure-reducing measures in high-rise building: A case analysis. Build. Serv. Eng. Res. Technol. 2018, 39, 505-517. [CrossRef]

7. Müller, T.M.; Leise, P.; Lorenz, I.S.; Altherr, L.C.; Pelz, P.F. Optimization and validation of pumping system design and operation for water supply in high-rise buildings. Optim. Eng. 2020, 1-44. [CrossRef]

8. Altherr, L.C.; Leise, P.; Pfetsch, M.E.; Schmitt, A. Resilient layout, design and operation of energy-efficient water distribution networks for high-rise buildings using MINLP. Optim. Eng. 2019, 20, 605-645. [CrossRef]

9. Waide, P.; Brunner, C.U. Energy-Efficiency Policy Opportunities for Electric Motor-Driven Systems; International Energy Agency (IEA) Energy Efficiency Series; Working Paper; IEA: Paris, France, 2011. Available online: https:/ /iea.blob.core.windows.net/assets/d6 9b2a76-feb9-4a74-a921-2490a8fefcdf/EE_for_ElectricSystems.pdf (accessed on 20 October 2021).

10. Kaya, D.; Yagmur, E.A.; Yigit, K.S.; Kilic, F.C.; Eren, A.S.; Celik, C. Energy efficiency in pumps. Energy Convers. Manag. 2008, 49, 1662-1673. [CrossRef]

11. Ruby, T.M. Innovation-enabling policy and regime transformation towards increased energy efficiency: The case of the circulator pump industry in Europe. J. Clean. Prod. 2015, 103, 574-585. [CrossRef]

12. IEC 60034-31. IEC 60034-31 Ed. 1.0 b:2010_Rotating Electrical Machines_Part 31: Selection of Energy-Efficient Motors Including Variable Speed Applications-Application Guide; International Electrotechnical Commission (IEC): Geneva, Switzerland, 2014.

13. ANSI/NEMA MG 1-2016 Motors and Generators; National Electrical Manufacturers Association (NEMA): Rosslyn, VA, USA, 2016.

14. De Almeida, A.; Fong, J.; Brunner, C.U.; Werle, R.; Van Werkhoven, M. New technology trends and policy needs in energy efficient motor systems-A major opportunity for energy and carbon savings. Renew. Sustain. Energy Rev. 2019, 115, 109384. [CrossRef]

15. de Almeida, A.T.; Ferreira, F.J.T.E.; Baoming, G. Beyond Induction Motors-Technology Trends to Move Up Efficiency. IEEE Trans. Ind. Appl. 2014, 50, 2103-2114. [CrossRef]

16. de Almeida, A.T.; Fonseca, P.; Fernando, J.T.E.; Ferreira, J.F. EUP Lot 11 Motors—Final; ISR—University of Coimbra: Coimbra, Portugal, 2008. Available online: https:/ / circabc.europa.eu/sd/d/62415be2-3d5a-4b3f-b29a-d1760f4dc11a/Lot11\%20Motors\% 201-8\%20final\%2028-04-08.pdf (accessed on 20 October 2021).

17. Arun Shankar, V.K.; Umashankar, S.; Paramasivam, S.; Hanigovszki, N. A comprehensive review on energy efficiency enhancement initiatives in centrifugal pumping system. Appl. Energy 2016, 181, 495-513. [CrossRef]

18. Krishnamoorthy, S.; Jayabal, D. Evaluation of transformer loading and energy loss for increasing energy efficiency in distribution system. In Proceedings of the ECTI-CON 2015-2015 12th International Conference on Electrical Engineering/Electronics, Computer, Telecommunications and Information Technology, Hua Hin, Thailand, 24-27 June 2015; Institute of Electrical and Electronics Engineers (IEEE): New Jersey, NJ, USA, 2015.

19. Kazakbaev, V.; Prakht, V.; Dmitrievskii, V.; Oshurbekov, S.; Golovanov, D. Life Cycle Energy Cost Assessment for Pump Units with Various Types of Line-Start Operating Motors Including Cable Losses. Energies 2020, 13, 3546. [CrossRef]

20. Kazakbaev, V.; Prakht, V.; Dmitrievskii, V.; Golovanov, D. Feasibility Study of Pump Units with Various Direct-On-Line Electric Motors Considering Cable and Transformer Losses. Appl. Sci. 2020, 10, 8120. [CrossRef]

21. Mitrovic, D.; Morillo, J.G.; Rodríguez Díaz, J.A.; Mc Nabola, A. Optimization-Based Methodology for Selection of Pump-asTurbine in Water Distribution Networks: Effects of Different Objectives and Machine Operation Limits on Best Efficiency Point. J. Water Resour. Plan. Manag. 2021, 147, 04021019. [CrossRef]

22. WSU Energy Program. A Sourcebook for Industry Advanced Manufacturing Office Improving Motor and Drive System Performance; WSU Energy Program: Washington, DC, USA, 2014. Available online: https://www.energy.gov/sites/prod/files/2014/04/f15/ amo_motors_sourcebook_web.pdf (accessed on 20 October 2021).

23. Bortoni, E.C.; Bernardes, J.V.; da Silva, P.V.V.; Faria, V.A.D.; Vieira, P.A.V. Evaluation of manufacturers strategies to obtain high-efficient induction motors. Sustain. Energy Technol. Assess. 2019, 31, 221-227. [CrossRef]

24. de Almeida, A.T.; Fong, J.; Falkner, H.; Bertoldi, P. Policy options to promote energy efficient electric motors and drives in the EU. Renew. Sustain. Energy Rev. 2017, 74, 1275-1286. [CrossRef]

25. Ferreira De Souza, D.; Antonio Marino Salotti, F.; Luis Sauer, I.; Tatizawa, H.; Gakiya Kanashiro, A. A Comparison between Reported Values and Measured Values of Power Factor and Efficiency for Electric Induction Motors. IEEE Lat. Am. Trans. 2021, 19, 173-181. [CrossRef]

26. Andrade, C.T.D.C.; Pontes, R.S.T. Economic analysis of Brazilian policies for energy efficient electric motors. Energy Policy 2017, 106, 315-325. [CrossRef]

27. Mahlia, T.M.I.; Yanti, P.A.A. Cost efficiency analysis and emission reduction by implementation of energy efficiency standards for electric motors. J. Clean. Prod. 2010, 18, 365-374. [CrossRef]

28. Bortoni, E.C.; Nogueira, L.A.H.; Cardoso, R.B.; Haddad, J.; Souza, E.P.; Dias, M.V.X.; Yamachita, R.A. Assessment of the achieved savings from induction motors energy efficiency labeling in Brazil. Energy Convers. Manag. 2013, 75, 734-740. [CrossRef] 
29. Safin, N.; Kazakbaev, V.; Prakht, V.; Dmitrievskii, V. Calculation of the efficiency and power consumption of induction IE2 and synchronous reluctance IE5 electric drives in the pump application based on the passport specification according to the IEC 60034-30-2. In Proceedings of the IEEE 2018 25th International Workshop on Electric Drives: Optimization in Control of Electric Drives (IWED), Moscow, Russia, 31 January-2 February 2018; pp. 1-5. [CrossRef]

30. Goman, V.; Oshurbekov, S.; Kazakbaev, V.; Prakht, V.; Dmitrievskii, V. Energy Efficiency Analysis of Fixed-Speed Pump Drives with Various Types of Motors. Appl. Sci. 2019, 9, 5295. [CrossRef]

31. Carravetta, A.; Giugni, M.; Malavasi, S. Application of innovative technologies for active control and energy efficiency in water supply systems. Water 2020, 12, 3278. [CrossRef]

32. Wong, L.T.; Mui, K.W.; Lau, C.P.; Zhou, Y. Pump Efficiency of Water Supply Systems in Buildings of Hong Kong. Energy Procedia 2014, 61, 335-338. [CrossRef]

33. Glover, A.; Lukaszczyk, M. Oversizing pump motors-The problems. World Pumps 2005, 2005, 36-38. [CrossRef]

34. Ahonen, T.; Orozco, S.M.; Ahola, J.; Tolvanen, J. Effect of electric motor efficiency and sizing on the energy efficiency in pumping systems. In Proceedings of the 2016 18th European Conference on Power Electronics and Applications, Karlsruhe, Germany, 5-8 September 2016. [CrossRef]

35. Horn, D.A. Progression of product energy efficiency requirements in the European union. In Proceedings of the 2017 IEEE Conference on Technologies for Sustainability (SusTech 2017), Phoenix, AZ, USA, 12-14 November 2017; pp. 1-5. [CrossRef]

36. Berardi, U. Building Energy Consumption in US, EU, and BRIC Countries. Procedia Eng. 2015, 118, 128-136. [CrossRef]

37. Goman, V.; Prakht, V.; Kazakbaev, V.; Dmitrievskii, V. Comparative Study of Induction Motors of IE2, IE3 and IE4 Efficiency Classes in Pump Applications Taking into Account $\mathrm{CO}_{2}$ Emission Intensity. Appl. Sci. 2020, 10, 8536. [CrossRef]

38. Soflaei, F.; Shokouhian, M.; Tabadkani, A.; Moslehi, H.; Berardi, U. A simulation-based model for courtyard housing design based on adaptive thermal comfort. J. Build. Eng. 2020,31, 101335. [CrossRef]

39. Brazilian Association of Technical Standards (ABNT). NBR 15704-1-Valves-Requirements and Test Methods Part 1: Single Handle Bath Valve for Plumbing Use; ABNT: Rio de Janeiro, Brazil, 2011.

40. Brazilian Association of Technical Standards (ABNT). NBR 5626-Cold and Hot Water Building Systems-Project, Execution, Operation and Maintenance; ABNT: Rio de Janeiro, Brazil, 2020.

41. Brazil, Interministerial Ordinance No. 1, of June 29, 2017. Establish the MEPS for Induction Three-Phase Electrical Motors with Squirrel-Cage Rotor Level IE3, Brazilian or Foreign Made. D.O.U., Brasilia-BR: 30 August 2017. Available online: https:/ / www.in.gov.br/materia/- /asset_publisher/Kujrw0TZC2Mb/content/id/19266787/do1-2017-08-30-portariainterministerial-n-1-de-29-de-junho-de-2017-19266690 (accessed on 20 October 2021).

42. Brazilian Association of Technical Standards (ABNT). NBR 5648-Pipes and Fittings of Poly (Vinyl Chloride) PVC-U with SolventWelded Joint for Predial Installation of Cold Water-Requirements; ABNT: Rio de Janeiro, Brazil, 2018. 